\title{
HERNIA E ACCIDENTE DO TRABALHO (*)
}

\author{
PROF. FLAMÍNIO FAVERO \\ (Cathedratico de Medicina Legal da Faculdade de Medicina da Univer- \\ sidade de São Paulo).
}

A questão da hernia em infortunistica é velho thema. Surgiu quando appareceram as primeiras leis especiaes de accidentes do trabalho. E' velho thema e largamente debatido. 'E os problemas que elle envolve ainda não tiveram solução definitiva, se é que um dia chegarão a tel-a.

Não penseis, deante dessa duvida que deixo expressa, tenha eu a pretensão de concorrer para tal proposito, ou deseje, por acaso, apresentar ponto de vista original. Longe de mim subir da modesta chinella que aprendi a coser. Quero, apenas, pôr em fóco o assumpto, condicionado á nossa nova lei de accidentes e dizer a minha orientação como perito, nas innumeras vezes que fui chamado a auxiliar a distribuição da Justiça.

Os debates em torno do assumpto se travaram entre duas correntes antagonicas: uma constituida por medicos, outra por juristas.

E. verdadeiramente difficil, na pratica, deante da applicação das leis em que a medicina deve intervir, conciliar essas duas classes. Veja-se a complexa questão da responsabilidade dos criminosos, pomo de interminavel discordia entre ambas, nos seus constantes malentendidos e preconceitos.

A hernia é assim. Para os juristas, na maioria das vezes, constitue ella accidente do trabalho, devendo, destarte, seu portador ser indemnisado do damno, cabendo o onus ao patrão. $O$ raciocinio dos que seguem essa corrente é baseado na apparencia dos factos: o exercicio do trabalho demanda esforço; o esforço póde produzir hernias; apparecendo estas no tempo do trabalho, a. indemnisação se impõe de direito.

Aos medicos repugna esse raciocinio demasiadamente simples. Para elles, a hernia accidente occorida em virtude do trabalho, consequencia directa deste, é a excepção. Em casos rarissimos se apresenta. $O$ que ha, em verdade, é uma doença antiga, preexistente, de evolução vagarosa. Não cabe ao empregado qualquer responsabilidade por ưm mal que não se liga necessaria, fatalmente ao trabalho.

(*) Conferencia realizada no Departamento Scientifico do Centro Academico Oswaldo Cruz, em 6-IV-1940. 
Pesada bem a argumentação de lado a lado, força é concluir que nenhum dos aversarios tem razão. Oscar Freire, meu saudoso mestre, em questões litigiosas assim, costumava dizer: nem tanto ao mar, nem tanto á terra. E bem se applica a expressão ao caso em apreço. A verdade está no meio termo. E é ao medico-legista que cabe dizela, porque este, ponto de união entre a medicina e o direito, iniciado nos segredos de ambas as sciencias, sabe o que quer a lei e conhece o que póde concluir a medicina. Mas, eu disse, o medico-legista, isto é, o especialista em medicina legal, que tenha feito já o seu tirocinio pratico, á sombra da mentalidade por que deve conduzir-se o technico. Porque ha peritos que são mestres em medicina clinica, mas desconhecem medicina legal e, pois, as verdadeiras necessidades da lei. São pessimos peritos, sabendo apenas fazer medicina legal em pilulas, na expressão jocosa de Filippi. Hoje, a era é das especialisações. Foi-se a do encyclopedismo. E a medicina legal é uma especialidade como outra qualquer, differindo apenas num pormenor talvez de minima valia: nisso que obriga os seus cultores a se esquecerem de que tambem de pão vive o homem.

O medicó-legista, pois, deve, para auxiliar a Justiça, saber o que são hernias e ter um seguro conceito de accidente do trabalho. De posse desses conhecimentos, reconhecerá as verdadeiras hernias accidentes do trabalho.

Permitti, assim, que eu toque na conceituação das hernias e na dos accidentes do trabalho. Depois, chegarei ao ponto nevralgico do assumpto.

\section{HERNIAS}

As hernias são o estado dos orgams que sahem das cavidades onde se acham contidos. Existem, pois, de todas as especies, considerando-se não só as grandes cavidades, mas, as demais, continentes dos orgams passiveis de exteriorisação. Assim, ha hernias do encephalo, dos pulmões, dos intestinos. Muitas dessas se identificam por denominações especificas. A expressão simples hernia, no consenso geral dos medicos e dos juristas, se reserva para a sahida do ińtestino da cavidade abdominal e, mais propriamente, para a sahida do intestino delgado. Trata-se, em verdade, da hernia mais frequente de modo que a quantidade impõe a denominação. E' sempre o direito do mais forte.

Os typos fundamentaes de hernia do intestino são: na parede posterior do abdome, a hernia lombar (pelo triangulo de Petit) e a hernia ischiatica (acima do musculo pyramidal); e na parede anterior do abdome, as hernias da linha branca (na llinha epigastrica), a hernia umbilical, a hernia crural, a hernia obturadora e a hernia inguinal, esta a mais frequente e a mais importante para a infortunistica, podendo ser tomada como typo entre todas. 
Segundo Forgue, que tem paginas magistraes a respeito (Path. Ext., Vol. II, pag. 408), "na etiologia das hernias interveem dois factores: um, preponderante, representado por todas as causas que diminuem a resistencia da parede. $O$ outro, accidental, que corresponde ao augmento da pressão abdominal". No primeiro grupo etiologico, estão as malformações congenitas, o enfraquecimento senil da musculatura parietal e a influencia da herança. Entre as causas responsaveis pelo augmento da pressão abdominal, assignalam-se: as profissões, a gravidez e os partos e certas doenças (Forgue).

\section{CONCEITO DE ACCIDENTE DO TRABALHO}

Que são accidentes do trabalho? "A lei anterior, de 1919, os definia da seguinte fórma: "consideram-se accidentes no trabalho, para os fins da presente lei: a) o produzido por uma causa subita, violenta, extrema e involuntaria no exercicio do trabalho, determinando lesões corporaes ou perturbaçôes funccionaes que constitúam a causa unica da morte, ou perda total ou parcial, permanente ou temporaria da capacidade para o trabalho; b) a molestia contrahida exclusivamente pelo exercicio do trabalho, quando este fôr de natureza a só por si causal-a, e desde que determine a morte do operario ou perda total ou parcial, permanente ou temporaria, da capacidade para o trabalho (art. 1. ${ }^{\circ}$ da lei 3.724 de 1919).

Para a caracterização do chamado accidente-typo, o da alinea $a$, era indispensavel a existencia de uma causa unica na producção do damno. A alinea $b$ se referia ás doenças profissionaes contrahidas exclusivamente pelo exercicio do trabalho, que devia ser idoneo para, só por si, causal-as.

Esse rigor deixava fóra do ambito de protecção legal innumeros males typicamente, genuinamente ligados ao trabalho. E dentre esses estariam, nem ha duvida, a maioria das hernias.

A lei vigente, que baixou com o decreto 24.637 de 10 de julho de 1934, é mais justa, permittindo solução consentanea com o verdadeiro espirito do direito novo dé protecção operaria. De facto, diz o art. 1. ${ }^{\circ}$ : "considera-se accidente do trabalho, para os fins da presente lei, toda lesão corporal, perturbação funcional ou doença produzida pelo exercicio do trabalho, ou em consequencia delle, que determine a morte ou a suspensão ou limitação permanente ou temporaria, total ou parcial, da capacidade para o trabalho.

$\S 10^{\circ}$ - São doenças profissionaes, para os effeitos da presente lei, além das' inherentes ou peculiares a determinados ramos de actívidade, as resultantes exclusivamente do exercicio, ou das condições especiaes ou excepcionaes em que o mesmo fôr realisado, não sendo assim consideradas as endemicas, quando por ellas forem attingidos empregados habitantes da região".

Nesses preceitos, está claro: $10^{\circ}$ - que o accidente indemnisavel é aquelle que surge pelo exercicio do trabalho ou em consequencia 
delle, exteriorisando-se o damno: a) numa lesão corporal, b) numa perturbação funccional ou, c) numa doença; $20^{\circ}$ - que o accidente póde ser produzido: a) instantaneamente ou não, pela actuação de uma causalidade concentrada, cuja epoca de incidencia é possivel precisar com rigor, constituindo o chamado acidente agudo ou typo; ou, b) mediatamente, a pouo e pouco, pela acção progressiva de uma causalidade diluida, cuja epoca de incidencia é impossivel precisar, sabendo-se apenas que foi pelo exercicio do trabalho ou pelas condições especiaes ou excepcionaes em que elle se effectuou, que surgiu o damno, constituindo na chamada doença- profissional.

\section{GRUPOS FUNDAMENTAES DE HERNIAS}

Com essas bases, tenho elementos para estudar o modo por que devem ser consideradas as hernias em nossa legislação.

$\mathrm{Na}$ pratica, no consenso geral dos tratadistas, é incontestavel haver três grupos fundamentaes de hernias quanto á genese de sua producção real ou apparente: $10^{\circ}-$ a hernia enfermidade; $2 .^{\circ}-\mathbf{a}$ hernia doença profissional; $30^{\circ}$ - a hernia accidente typo.

$1 .^{\circ}$ - Hernia enfermidade - Neste grupo estão as hernias em cuja producção o trabalho não concorre, proxima ou remotamente. Preexistem á actividade profissional do operario, e são devidas a uma disposição constitucional do seu portador. Apresentando-se ao trabalho, o operario já tem a sua hernia mais ou menos volumosa, de um lado ou de ambos, facilmente verificavel pelo exame objectivo. Póde succeder, entretanto, que o exame previo não se realise, e a hernia se mostre após um esforço minimo no trabalho, como o faria fôra do trabalho. $E$ duas contingencias devem ser attentidas na solução do problema que a applicação da lei então envolve: primeira o operario não notára, anteriormente, a natureza do seu mal e, como se exteriorisou este no trabalho, attribue-o, de boa fé, ao exercicio de sua actividade; a segunda contingencia é a do operario que se sabia doente, mas, procura, agindo de má fé, levar á conta do trabalho a origem do seu mal, para tirar proveito.

Quando falo de hernia enfermidade, eu me refiro ás hernias reaes, typicas, de diagnostico incontestavel, accessivel este ao exame posterior do perito. A exclusão do accidente do trabalho, em regra, se impõe. Não inclúo nesse grupo as chamadas predisposições herniarias, e isto por algumas razões que apresentarei mais adeante.

$2 .^{\circ}$ - Hernia doença profissional - Chama-se assim, aquella hernia que surge no decorrer do trabalho mais ou menos longo, mais ou menos pesado. Não apparece de chofre, abruptámente, num esforço unico, violento, excessivo, mas, sim, pela reiteração de esforços, demandando semanas, mezes, annos de trabalho - doença profissional que é, equiparada a uma intoxicação chronica pelo chumbo, pelo arsenico, pelo phosphoro ou a uma tuberculose pulmonar. 
Mas, dir-se-á, tal hernia não surgirá se não houver um terrenó preparado para ella, ao contrario do que succede com o saturnismo, o arsenicismo, o phosphorismo.

De accôrdo. Mas, com a tuberculose pulmonar é a mesma circumstancia. Apenas o ambiente hostil, o trabalho exagerado, a alimentação inadequada, a hygiene imperfeita não crearão a tuberculose. Essas causas adversas vão actuar sobre um fóco latente do mal, silencioso, inocuo, oriundo de uma primo-infecção infantil ou não, e só depois a somma dessas parcellas - a preexistencia e a superveniencia de anormalidades - deflagrará o estado morbido, doença profissional indemnisavel, desde que o trabalho foi o factor que produziu taes causas adversas.

Devessemos excluir no operario qualquer preexistencia anormal ou morbida, e quasi não haveria damno indemnisavel, ficando burlada, assim, a acção social da lei de accidentes do trabalho.

No caso da tuberculose pulmonar, é razoavel a procedencia dessa conclusão. Nas grandes cidades, sobretudo, as estatisticas demonstram que a maioria dos individuos tem lesões tuberculosas mais ou menos latentes, mais ou menos cicatrisadas. Imaginae se a prova de absoluta hygidez previa fôsse exigida para os operarios. Seria inoperante e anodyma a lei de sua protecção.

$\mathrm{O}$ operario vale pelo trabalho que realisa na occasião em que se entrega ás suas actividades. Se esse é efficiente, mas, no decorrer delle um mal que não estava imminente irrompe pelas condições do serviço, iśto perfeitamente admittido e demonstrado, então, um estado anterior não pesará, ainda que o accidente seja simples aggravação da preexistencia anormal ou morbida.

Isto é pacifico hoje, na jurisprudencia. $E^{\prime}$ do espirito da lei. E' mesmo de sua lettra.

Ora, em thema de hernia, a questão é identica. Não importa que haja predisposição herniaria. Si hernia não existia, a predisposição era compativel com a plena efficiencia do trabalho. Este, pelas suas condições de reinteração traumatisante, agiu atrávez de esforços na predisposição e deu, como resultado, a hernia. 'Será a hernia doentça profissional indemnisavel.

E' a these que defendo em minha actuação pericial, e me parece certa. De facto. Que é predisposição herniaria? Transcrevo de Oller ("La Práctica Médica en los accidentes del Trabajo", Madrid, Javier Morata, 1929 pag. 78), o seguinte ttrecho: "Para uns autores é sómente a dilatação do conducto inguinal; para outros, a ponta de hernia, a debilidade das paredes, etc. Para Zollinguer são necessarias algumas condições seguintes: $1 .^{\mathrm{a}}$, annel inguinal exterior dilatado, com bordos delgados; $2 .^{\mathrm{a}}$, canal inguinal curto e recto; $3 .^{\mathrm{a}}$, musculos e fascias debeis; choque intestinal contra os dedos introduzidos no canal; 4. ${ }^{\mathrm{a}}$, canal inguinal fraco; $5 .^{\mathrm{a}}$ ponta de hernia; $6 .^{\mathrm{a}}$, descida muito pronunciada dos testiculos; 7. a, varicocelle"

Ora, sendo assim, notae o que ainda observa o mesmo autor: "de 4.836 operarios examinados por Zollinguer naquella data, 3.104 
tinham predisposição. Cifira tão exageradamente alta, nós a assignalavamos, e von Hassel affirmava que ern $75 \%$ dos operarios ha predisposição".

Commentando esse facto, o mesmo autor (Oller) assim conclúe: "quer dizer que um exame medico escrupuloso, muito pormenorisado póde fazer que a imensa maioria dos operarios examinados ten'na predisposição herniaria. Semelhante attitude, ainda que muito legal e muito scientifica, parece-nos francamente exagerada".

Consideráe se sómente $25 \%$ dos operarios pudessem, ser acceitos para o trabalho, ou ter um accidente indemnisavel quando herniados em serviço. Que reduzido campo de applicação da lei de infortunios! $\mathrm{E}$ para que esse direito novo, explendida conquista destas ultimas decadas dos povos civilisados? Ficassemos então na lei commum.

Deante disso, a minha conclusão não é sentimental, mas, logica.

Assim, são hernias-doenças profissionaes, no meu entender, aquellas que surgem em individuos predispostos ou não, após reiterado esforço que o trabalho habitualmente exige, sendo impossivel dizer a occasião exata do seu apparecimento.

3 - Hernia accidente typo - Este ultimo grupo é de mais facil diagnostico, todavia; mais raramente se apresenta.

O operario é ou não um predisposto. O trabalho habitual não iria produzir qualquer damno: 'Entretanto, um esforço agudo, violento, anormal; imprevisto, ou um traumatismo local, intenso, determina a hernia. São mais ou menos as condições exigidas nas tabellas officiaes de accidentes. Accrescento, apenas, o que me parece de justiça, a possibilidade de uma predisposição herniana não invalidar a conceituação do nexo de causa e effeito.

Existem taes hernias? Sim, nem ha duvida. Produzidas na occasião de um esforço anormal, imprevisto e violènto no exercicio do trabalho, em individuos predispostos, já tive o ensejo de observalas em minha pratica de perito. E pela prova testemunhal a ellas se seguiu, de facto, aquella dramaticidade de signaes exigida pelos mestres no assumpto e pela jurisprudencia franceza, belga, allemã, suissa, etc. : apparecimento prompto da hernia com dôres intensas, e necessidade de interromper immediatamente o trabalho.

E' claro que o elemento dôr é muito pessoal, cada um de nós reagindo differentemente aos estimulos dolorosos. Entretanto, a argucia pericial encontrará elementos para uma conclusão affirmativa ou negativa.

Quanto ás hernias originadas de um trauma local, violento, são rarissimas, mas, existem egualmente. Veja-se, a proposito, o testemunho de David Giordano, conhecido cirurgião de Veneza, em suas "Lezioni di Clinica Chirurgica" E' elle insuspeito porque rigoroso em extremo, ao exagero até, na admissão das hernias accidentes. São suas as seguintes palavras: "querendo agora resumir em breve e pratico conceito as questões de que viemos discorrendo, desejaria que retivesseis ser a hernia um infortunio anatomico que um infortunio 
no trabalho póde, com extrema raridade, reproduzir, quer depois de um trauma directo que viola a integridade anatomica da região, ou immediatamente, depois de um esforço insolito. Este, porém, segundo penso, poderá mais tornar manifesta do que crear uma hernia".

$\mathrm{E}$ o mesmo autor se refere a quatro hernias, apenas quatro, que teve a opportunidade de vêr, do typo daquellas consequentes a- um trauma local, sendo uma desejada e trếs accidentaes. A primeira referia-se a um velho com volumosa hernia escrotal, produzida 50 annos antes: não desejando fazer o serviço militar, estando em Paris, procurou um especialista nessas cousas, que the collocou no canal inguinal "um instrumento semelhante aquelles que se usam para dilatar os dedos das luvas" e depois fel-o acamar-se, applicando ainda, no local, emplastros irritantes; um mez depois, surgiu a hernia.

Outro caso, é de individuo irmão e avô de herniados, com 60 annos, que cahiu sobre o espaldar de uma cadeira e feriu-se na região inguinal, onde se formou volumoso hematoma; 2 mezes após, surgiu a hernia.

O terceiro caso se refere a um guarda que recebeu um ponta pé na região inguinal. No segundo mez, surgiu uma hernia.

O ultimo, por fim, diz respeito a um medico que, cahindo, sé feriu com um cabo de guarda-chuva na região inguinal. Após 2 mezes, surgiu uma hernia na região.

$$
\text { * * * }
$$

Ahi estão as bases fundamentaes para a solução do problema das hernias em infortunistica.

Eu poderia, agora, desenvolver suavemente minha disertação, illustrando-a com obsèrvações proprias ou alheias. Seria criminosa, entretanto, a minha attitude se eu prolongasse por mais tempo, numa occasião festiva como esta, a minha palestra.

Quero apenas, como fecho do trabalho, apresentar-vos as seguintes conclusões:

1. ${ }^{a}$ - As pericias em infortunistica devem ser feitas por medicos conhecedores do aspecto medico e do aspecto juridico da questão, sendo preferiveis os medicos legistas.

2. a - Não ha, para solução de cada caso de allegação de hernia accidente, normas seguras, irremoviveis, de caracter exclusivamente objectivo. Mas, como succede em outras pericias, dentre as quaes é typica a da deformidade, a interpretação do perito e, pois, o factor subjectivo, é de grande relevancia. Por isso, a experiencia, o treino, a pratica pericial se impõem.

$3 .^{a}$ - Hoje, não se deve mais falar em hernia de força e hernia de fraqueza. Ambas pódem ser ou deixar de ser accidentes indemnisaveis. $O$ que ha é hernia accidente do trabalho e hernia não accidente do trabalho. 
4. ${ }^{\mathrm{a}}$ - A lei não exige, hoje, a caüsalidade unica na produção do accidente typo. Assim, não se deve buscar uma etiologia unica na formação da hernia. Para a diagnose, deante disso, diversos informes convem reunir: a) o operario, embora predisposto, trabalhava efficientemente e não estava em imminencia de ter uma hernia ; b) o trabalho exigiu esforço ou motivou trauma idoneo para a produção proxima ou remota da hernia; c) a hernia póde ter, de facto, o seu nexo de ligação com o esforço ou trauma do trabalho, não sendo uma simples coincidencia de local e tempo, o seu apparecimento.

5. ${ }^{\mathrm{a}}$ - A intervenção cirurgica é o remedio radical para as hernias. Restabelecido o operario, em cerca de um mez retomará as suas actividades. Nessas condições, a solução de escolha para o problema das hernias accidentes ou allegadas taes, é esse, de interesse para o operario ',para o empregador e para a sociedade. Entretanto, tal solução deve ser acceita voluntariamente pelo operario. Uma imposição repugna ao direito constituido e á ethica geral. Se o operario se recusar a essa solução ideal, então indemnise-se a sua incapacidade parcial e permanente, conforme a justiça.

$6^{\text {a }}$ - Feita a intervenção cirurgica, surgindo complicações ou havendo rescidiva durante o trabalho, é claro que o onus deve pesar sobre o empregador.

Ahi está, em synthese, como entendo o problema das hernias em infortunistica.

E é nos subsidios dessa minha comprehensão, que soluciono ois casos que me são submettidos a exame.

Estarei certo? Estarei errado?

Se a medicina e o direito me oppuserem restricções a essa conducta, as leis de humanidade me applaudem. E convireis que, entre as leis da razão e as do coração, sabem melhor as ultimas. Dellas é que o mundo mais necessita. 